\title{
EFFECTS OF DIFFERENT HEAT TREATMENTS ON THE CHEMICAL AND MICROBIOLOGICAL CHARACTERISTICS OF EGG-FREE AND QUAIL EGG DRIED PASTA
}

\author{
ILDIKÓ SZEDLJAK *1, VIKTÓRIA TÓTH ${ }^{1}$, JUDIT TORMÁSI ${ }^{1}$, ANIKÓ KOVÁCS ${ }^{1}$, LÁSZLÓ SOMOGYI ${ }^{1}$, \\ LÁSZLÓ SIPOS², AND GABRIELLA KISKÓ3 \\ ${ }^{1}$ Department of Grain and Industrial Plant Processing, Faculty of Food Science, Szent István University, \\ Villányi út 23, Budapest, 1113, HUNGARY \\ ${ }^{2}$ Department of Logistics and Sensory Analysis, Faculty of Food Science, Szent István University, Villányi út \\ 23, Budapest, 1113, HUNGARY \\ ${ }^{3}$ Department of Microbiology and Biotechnology, Faculty of Food Science, Szent István University, Villányi \\ út 23, Budapest, 1113, HUNGARY
}

\begin{abstract}
In Hungary, dried pasta products are very popular amongst all groups of society. In recent years the demand for not only dried pasta made from hen eggs (Gallus gallus domesticus) but from alternative types of ingredients has increased. However, according to the literature the chemical and microbiological characteristics of this type of pasta have yet to be studied in depth. The effects of the use of quail eggs and heat treatments at different temperatures were studied by chemical and microbiological measurements. The activity of oxidative enzymes and nutritional characteristics (watersoluble total polyphenol content, water-soluble antioxidant capacity, peroxidase enzymatic activity, water-soluble protein content and yellow pigment content) was tested during our experiments. The data were evaluated by relevant statistical methods. Significant differences were found both between heat treatments and between the egg content of the dried pasta samples. The peroxidase enzymatic activity and yellow pigment content increased with temperature. However, the usage of quail eggs provides a higher water-soluble protein content and water-soluble antioxidant capacity. The presence of microorganisms is decreased by increasing the drying temperature. The number of all the examined microorganisms was within limits.
\end{abstract}

Keywords: dried pasta, quail egg, heat treatment, chemical and microbiological characteristics

\section{Introduction}

Present-day problems of globalization have led to a need for more diverse, long-lasting and convenient food products of high nutritional value. Mindful consumers look for products that have positive physiological effects and have been subject to a minimal degree of processing.

In Hungary, dried pasta products are popular amongst all groups of society. Their position in the global market is safe because these products possess all of the aforementioned qualities and fall within an affordable price range too. The amount of dried pasta products consumed in recent years has elevated [1], therefore, the food industry continuously tries to lower production costs as well as improve profits and their nutritional value [2].

One of the important ingredients of pasta are eggs. For the industrial processing of dried pasta only two kinds of eggs are usable; hen and quail eggs.

The most commonly used type of eggs are hen eggs (Gallus gallus domesticus). Pasta products made from

\footnotetext{
*Correspondence: ildiko.szedljak@gmail.com
}

this type of eggs have been well studied. However, recently a need has emerged for more unconventional dried pastas made from alternative ingredients [3].

Quail egg pasta (Coturnix coturnix) is one of these innovations. Quail eggs as an ingredient are of a relatively high nutritional value. When compared to hen eggs they possess more protein but less carbohydrate and fat [4].

Chemical changes during processing define the quality of the end product. The most determinative factors are the temperature of the drying process and its changes during the process [5]. Significant changes in chemical behavior occur even at lower temperatures. Enzymeactivated changes like protein denaturation and pigment oxidation take place below $60^{\circ} \mathrm{C}$. At temperatures higher than $80{ }^{\circ} \mathrm{C}$ the oxidative enzymes deactivate and the Maillard reaction occurs, simultaneously the lysine concentration of the pasta decreases [6]. Therefore, choosing the most suitable drying temperature is an important step when it comes to the quality of the heat-treated products, especially in the case of dried pastas.

When designing and processing products with long 
storage and shelf lives, another important concern is the microbiological safety of the product. With the diminished water activity of these kinds of foods, the activity of microorganisms also decreases. The main parameter in this case is the number of microorganisms when processing commences. During drying the microbes deactivate and their numbers decrease [7].

Chemical and microbiological properties depend on the nutritional characteristics and drying properties of the pasta. Since the chemical and microbiological characteristics of quail egg pasta, according to the literature, have yet to be studied in depth, our goal was to expand this knowledge. Studying the properties of this product is beneficial to both advancing the technology and food safety.

\section{Experimental}

The aim of our study was to examine and compare the chemical and microbiological characteristics of the eggfree and quail egg dried pasta that had been subjected to different heat treatments. Changes caused by the presence of quail eggs were sought. Differences made by varying the temperature of heat treatments were examined. Moreover, a connection between the microbiome and heat treatments was characterized.

Materials The wheat flour, Triticum aestivum L., used and the quail eggs were bought from commercial sources. The reagents for the chemical and microbiological measurements were provided by Reanal Laborvegyszer Kereskedelmi Kft. The bacterial substrates were produced by Merck Kft.

Samples The tests were conducted on the samples of egg-free and "four hen egg pasta" doughs using sufficient quantities of quail eggs.

All the pastas were made from Triticum aestivum $L$. flour, water and quail eggs for the egg pasta. To improve the heat distribution the pastas were shaped into the form of linguine. The pasta doughs were treated at three different temperatures $\left(40^{\circ} \mathrm{C}, 60^{\circ} \mathrm{C}\right.$ and $\left.80^{\circ} \mathrm{C}\right)$ for twenty-five minutes in an Armfield-type fluid bed dryer.

The samples were subjected to chemical and microbiological measurements. In preparation for the chemical tests the samples were first grated then $100 \mathrm{mg} / \mathrm{ml} \mathrm{ex-}$ tracts were taken using distilled water. Every analytical method was conducted on five parallel samples.

Chemical Analysis The moisture content was determined by an MA50 Sartorius Moisture Analyzer. The water activity was measured by a Novasina MS1 water activity meter. For the measurement of color the Konica Minolta CR-310 Chroma Meter with a tristimulant objective in a laboratory coordinate system was used. To measure the pH, the SG23 Mettler-Toledo SevenGo Duo $\mathrm{pH} /$ conductivity meter was used. The acid values of the extracted samples were titrated with $0.1 \mathrm{M} \mathrm{NaOH}$ solution in the presence of the indicator phenolphthalein. The determination of $\mathrm{pH}$ and acid value was conducted based on Hungarian standards [8].

The water-soluble total polyphenol content was measured by Folin-Ciocalteu reagent [9] and expressed in gallic acid equvalent (GAE). Water-soluble antioxidant capacity was measured using a FRAP (ferric reducing antioxidant power) Assay Kit [10]. The peroxidase enzymatic activity was given by using ODA (o-dianisidine) as a hydrogen donor [11] and the data converted into ascorbic acid equivalent (AAE). For measuring the watersoluble protein content, a method by Layne [12] was used. The yellow pigment content of the samples was determined according to Hungarian standards extracted by butanol [13].

Microbiological Analysis Microbiological measurements were conducted given the relevant standards [1416]. Three parallel measurements were made from each sample. All samples were tested for coliform bacteria, Staphylococcus aureus and molds. In addition, the presence of Salmonella using a European standard [17] was tested for.

Statistical Evaluation All the measurements were replicated five times using XLSTAT software [18]. Given the parallel samples, non-parametric probes were used. The Kruskal-Wallis test was applied to calculate the $p$ value $(\alpha=0.05)$ and Dunn's post hoc pair-wise test was used with Bonferroni correction on significant results. The correlation between parameters was determined by Spearman's rank correlation coefficient (non-parametric equivalent of Pearson's correlation) $(\alpha=0.05)$.

\section{Results and Analysis}

\subsection{Chemical Analysis}

Moisture content The moisture content of the dried pasta samples decreased as the temperature of heat treatment increased. The moisture content of all the dried pasta products was below the maximum set by Hungarian standards [19] of $13 \%$. When treated at the same temperature the quail egg pastas always contained less moisture than the egg-free samples. However, significant differences were not determined.

Water activity This parameter is important for determining the initial microbial count and activity of samples during storage. The water activity of the samples decreased as the temperature of the heat treatment increased. In the quail egg pastas, the numbers were higher $\left(\right.$ aw $\left.\left(80^{\circ} \mathrm{C}\right)=0.6254 \pm 0.0313\right)$ compared to commercially available pastas (aw $<0.6$ ). Thus, at this level of water activity the xerotolerant and xerofil microbes could survive and reproduce. A significant difference was not determined. 


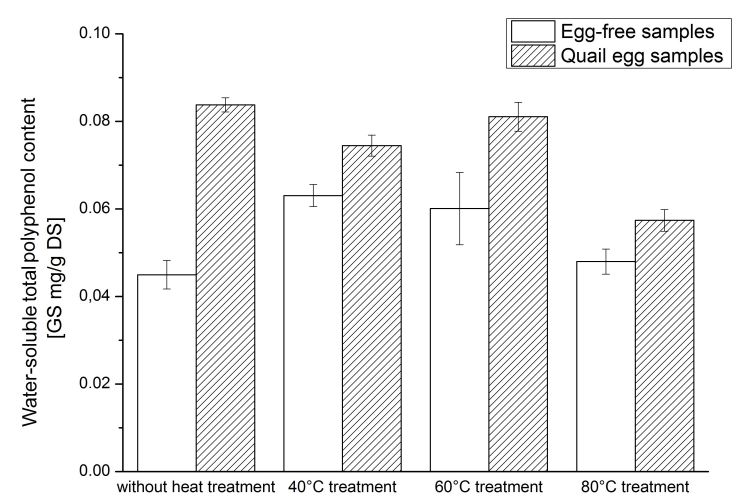

Figure 1: Water-soluble total polyphenol content of the samples in $\mathrm{mg} / \mathrm{g}$ gallic acid equivalent.

pH The pH also plays a key role in the reproduction and survival of microorganisms as well as in the activity of peroxidase. The $\mathrm{pH}$ of the quail egg samples was always lower than the egg-free samples. A significant difference was only measured in the quail egg $(3.572 \pm 0.128)$ and egg-free $(5.898 \pm 0.019)$ samples treated at $40{ }^{\circ} \mathrm{C}$. Since the molds are capable of reproducing at a lower $\mathrm{pH}(\mathrm{pH}=2-4)$ [20], this value of the quail egg pasta poses a threat from a microbiological point of view.

Acid value (AV) This parameter was always lower in the quail egg samples. In the samples dried at $60{ }^{\circ} \mathrm{C}$, significant differences were observed. All the acid values of measured samples were between 3.15 and 3.66 ${ }^{\circ} \mathrm{SH}$, which falls within the Codex Alimentarius Hungaricus' guidelines [19] (in dried pastas $\mathrm{AV}=$ maximum of $\left.5{ }^{\circ} \mathrm{SH}\right)$.

Water-soluble total polyphenol content For evaluating the water-soluble total polyphenol content (TPC) of the samples, the data was calibrated with the gallic acid equivalent as shown in Fig. 1, which gives the polyphenolic components in $\mathrm{mg}$ of gallic acid equivalent found in 1 gram of dried pasta.

The presence of the quail eggs resulted in higher water-soluble total polyphenol contents in each case. Significant differences based on the coupled comparison's $p$ values were only observed between the samples that were not heat treated.

Based on the results of the Kruskal-Wallis test a significant difference is observed between the TPC values of quail egg pastas. Among the quail egg samples, based on the comparison of pairwise $p$-values, a difference is found for at least two samples. This can be detected between the samples that were not heat treated and those treated at 80 ${ }^{\circ} \mathrm{C}$ as well as between samples treated at $60{ }^{\circ} \mathrm{C}$ and at 80 ${ }^{\circ} \mathrm{C}$.

Based on these results, it can be stated that the TPC may be influenced by heat treatment.

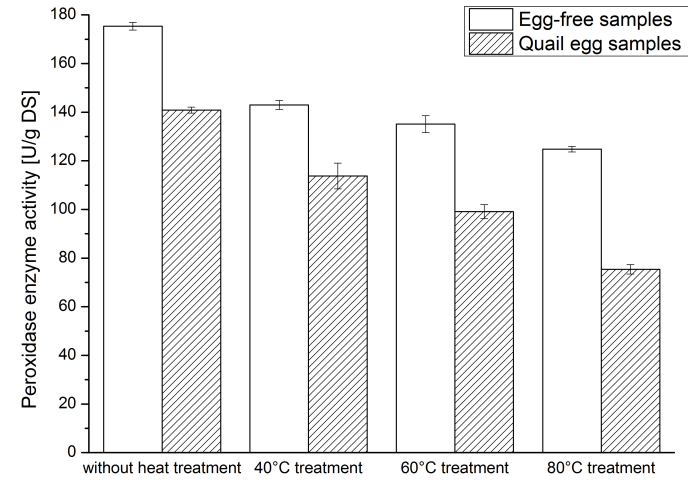

Figure 2: Peroxidase enzyme activity of the samples in $\mathrm{U} / \mathrm{g}$ DS.

Peroxidase enzymatic activity The peroxidase enzymatic activity was calculated on the basis of data from the literature and its value was given in terms of dry matter content (Björkstén, 1968). The graph in Fig. 2 clearly shows the effect of heat treatment. The enzymatic activity decreases as the temperature of the heat treatment increases and is always lower in the quail egg samples. The cause of this difference could be the different $\mathrm{pH}$ of the two types of pastas.

In both cases a significant difference is observed between the samples treated at $60{ }^{\circ} \mathrm{C}$ and those not subjected to heat treatment. In the results of the egg-free pastas, the decline is less than in the quail egg samples.

Water-soluble protein content The water-soluble protein content was always higher in the quail egg samples. Significant differences were observed between both the separate and cumulative evaluations. A significant difference was measured in the $p$-values in terms of the comparison of egg content when heat treated at $40{ }^{\circ} \mathrm{C}$. In addition differences were observed between the eggfree samples that were not subjected to heat treatment and those heat treated at $80{ }^{\circ} \mathrm{C}$, as well as between the quail egg samples that were not heat treated and those treated at $40{ }^{\circ} \mathrm{C}$ and $80^{\circ} \mathrm{C}$.

From these results it can be stated that the examined treatments influence the water-soluble protein content of the samples.

Water-soluble antioxidant capacity The measurements of the water-soluble antioxidant capacity were converted into ascorbic acid equivalent. The antioxidant capacity of the pastas rose as the temperature of the heat treatments increased, in terms of the egg-free samples, the maximum was observed at $60{ }^{\circ} \mathrm{C}$. The statistical evaluation revealed significant differences in every case. The increase in the antioxidant capacity as the temperature of heat treatment rises is common in the literature [21,22]. 


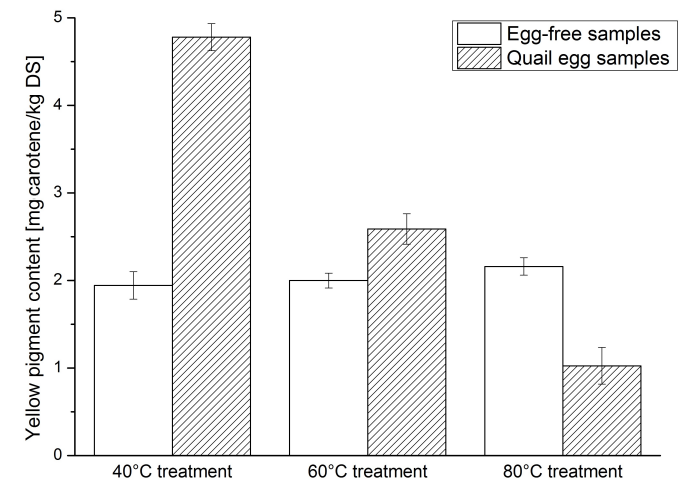

Figure 3: Yellow pigment content of samples given in $\mathrm{mg}$ carotene/kg DS.

Yellow pigment content and color measurement The yellow pigment content was only measured on samples of dried pasta. Both the egg-free and quail egg pastas exhibited significant differences between samples treated at 40 ${ }^{\circ} \mathrm{C}$ and $80^{\circ} \mathrm{C}$. As seen in Fig. 3 in the case of the quail egg samples, a significant decline in the yellow pigment content was observed as the temperature of heat treatment increased. Even so, the noticeable drop in the yellow pigment content of quail egg samples was still higher than in the case of the egg-free samples (except for the decline at $80{ }^{\circ} \mathrm{C}$ ).

For the assessment of color the "LAB" color chart was used. The $L^{*}$ value denotes the lightness and positive rate of the $b^{*}$ value which represents the intensity of the color yellow. Neither of these two values changed significantly in the presence of the quail eggs. However, the heat treatment resulted in significant changes in both color rates. A significant change in the lightness has already been observed in all the samples treated at $40{ }^{\circ} \mathrm{C}$. As shown in Fig. 4 the $b^{*}$ value increased as the temperature of heat treatment rose, therefore, the pastas became yellower as the temperature increased. In both types of pastas, significant differences were observed between

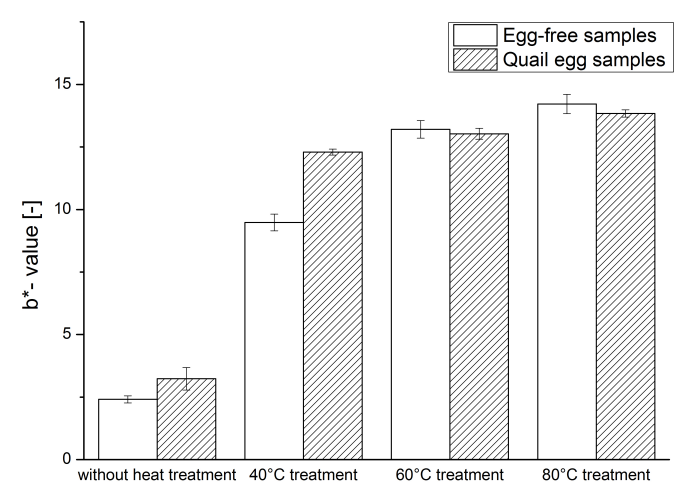

Figure 4: Yellow color intensity of samples from the CIELAB color space.

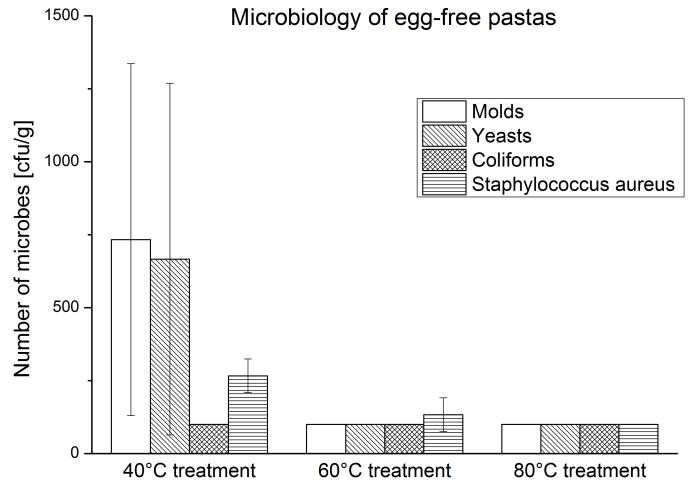

Figure 5: The results of the microbiological analysis of egg-free pastas.

the samples that were not subjected to heat treatment and those treated at higher temperatures $\left(60^{\circ} \mathrm{C}\right.$ and $\left.80^{\circ} \mathrm{C}\right)$.

The results of the yellow pigment content and color measurements are controversial in terms of the quail egg samples. The $b^{*}$ value - which shows the intensity of the color yellow - increases while the yellow pigment content decreases. The seemingly ambiguous data might be caused by chemical and microbiological changes not examined by us.

The yellow pigment content continuously decreases during the drying process, therefore, choosing the most suitable drying temperature is critical. From these results, to retain the maximum amount of yellow pigments in the finished products, heat treatment at $60{ }^{\circ} \mathrm{C}$ is recommended.

\subsection{Microbiological measurements}

The microbiological contamination of egg-free samples remained below the limit (Figs. 5 and 6).

However, in the case of the quail egg pasta, the coliform bacteria appeared in the samples treated at $40{ }^{\circ} \mathrm{C}$. The presence of the coliforms is not surprising since they

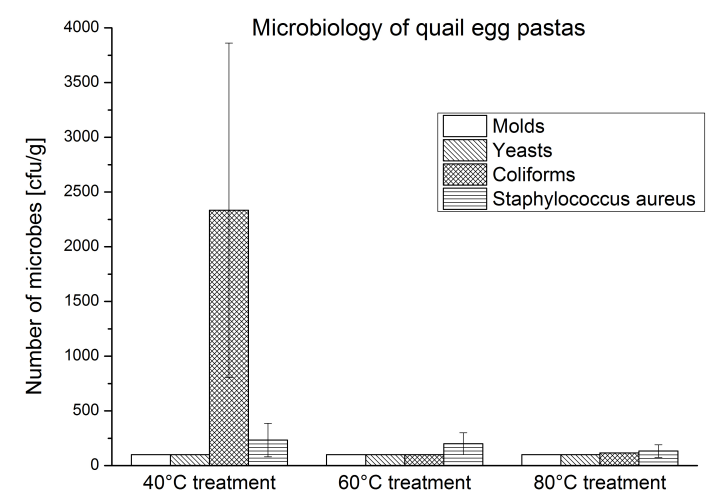

Figure 6: The results of the microbiological analysis of quail egg pastas. 
Table 1: Spearman correlation matrix of the six studied parameters, " $r$ " values ( $r=0$ no linear correlation, $r=-1$ perfect negative correlation, $r=1$ perfect positive correlation).

\begin{tabular}{lllllll}
\hline Variables & POX & TPC & $L^{*}$ & $b^{*}$ & $\begin{array}{l}\text { Antioxidant } \\
\text { capacity }\end{array}$ & $\begin{array}{l}\text { Yellow pigment } \\
\text { content }\end{array}$ \\
\hline Peroxidase enzymatic activity & $\mathbf{0}$ & 0.2283 & $\mathbf{0 . 0 0 0 0}$ & $\mathbf{0 . 0 1 5 9}$ & 0.7815 & 0.8270 \\
Total polyphenol content & 0.2283 & $\mathbf{0}$ & 0.0502 & $\mathbf{0 . 0 0 0 9}$ & $\mathbf{0 . 0 0 0 1}$ & $\mathbf{0 . 0 0 2 4}$ \\
$L^{*}$ & $<\mathbf{0 . 0 0 0 1}$ & 0.0502 & $\mathbf{0}$ & 0.5675 & 0.6137 & 0.4238 \\
$b^{*}$ & $\mathbf{0 . 0 1 5 9}$ & $\mathbf{0 . 0 0 0 9}$ & 0.5675 & $\mathbf{0}$ & $\mathbf{0 . 0 0 1 6}$ & 0.1523 \\
Antioxidant capacity & 0.7815 & $\mathbf{0 . 0 0 0 1}$ & 0.6137 & $\mathbf{0 . 0 0 1 6}$ & $\mathbf{0}$ & 0.1723 \\
Yellow pigment content & 0.8270 & $\mathbf{0 . 0 0 2 4}$ & 0.4238 & 0.1523 & 0.1723 & $\mathbf{0}$ \\
\hline
\end{tabular}

Values in bold are different from 0 with a significance level $\alpha=0.05$

Table 2: Spearman coefficient determination matrix of the six studied parameters, " $p$ " values

\begin{tabular}{lllllll}
\hline Variables & POX & TPC & $L^{*}$ & $b^{*}$ & $\begin{array}{l}\text { Antioxidant } \\
\text { capacity }\end{array}$ & $\begin{array}{l}\text { Yellow pigment } \\
\text { content }\end{array}$ \\
\hline Peroxidase enzymatic activity & $\mathbf{1}$ & 0.0512 & 0.4894 & 0.1930 & 0.0028 & 0.0017 \\
Total polyphenol content & 0.0512 & $\mathbf{1}$ & 0.1307 & 0.3397 & 0.4304 & 0.2910 \\
L* $^{*}$ & 0.4894 & 0.1307 & $\mathbf{1}$ & 0.0117 & 0.0092 & 0.0228 \\
$\mathrm{~b}^{*}$ & 0.1930 & 0.3397 & 0.0117 & $\mathbf{1}$ & 0.3118 & 0.0717 \\
Antioxidant capacity & 0.0028 & 0.4304 & 0.0092 & 0.3118 & $\mathbf{1}$ & 0.0653 \\
Yellow pigment content & 0.0017 & 0.2910 & 0.0228 & 0.0717 & 0.0653 & $\mathbf{1}$ \\
\hline
\end{tabular}

are found in the feces of warm-blooded animals (Bíró, 2014). As a result of the heat treatment the number of microbes decreased in both types of pasta. Based on these results it can be clearly seen that heat treatment increases the quality of both types of pasta from a microbiological standpoint. The higher the temperature of the heat treatment, the more microbiologically advantageous it is.

\subsection{Statistical evaluation}

In addition to the examination of significant differences between our data, correlation studies were conducted on six selected variables of the evaluated factors: peroxidase enzymatic activity (POX), water-soluble total polyphenol content (TPC), $L^{*}$ and $b^{*}$ values, yellow pigment content and water-soluble antioxidant capacity. Since five parallel measurements were taken, Spearman correlations were determined [23], which is the nonparametric equivalent of the Pearson's correlation.

Based on the obtained " $r$ " and " $p$ " values (Tables 1 and 2), two positive and three negative correlations were identified. The positive correlations were between the water-soluble total polyphenol content and yellow pigment content as well as between the water-soluble antioxidant capacity and $b^{*}$ values. The negative correlations were identified between the peroxidase enzymatic activity and $L^{*}$ value as well as $b^{*}$ values, the water-soluble total polyphenol content and $b^{*}$ values, in addition to the water-soluble total polyphenol content and water-soluble antioxidant capacity.

\section{Conclusion}

The aim of this study was to expand the literature on the chemical and microbiological characteristics of quail-egg dried pastas.

With regard to the nutritional value of the pastas almost all of the examined characteristics declined as the temperature of the heat treatment increased except for the water-soluble antioxidant capacity. From our study it was found that the heat treatments at $80{ }^{\circ} \mathrm{C}$ were the most effective. Based on these results, heat treatments at high temperatures $\left(80{ }^{\circ} \mathrm{C}\right)$ are recommended especially from a microbiological point of view. The samples should also be maintained at this temperature for at least twenty-five minutes. Such treatment would ensure the production of higher quality and safer products.

While the industrial use of quail eggs causes technological and economic problems, this study could be a starting point for further research in this field.

\section{REFERENCES}

[1] International Pasta Organization - Survey. The world pasta industry in 2012; 2013. 
http://www.internationalpasta.org

[2] Kumar S. B., Prabhasankar P., Low glycemic index ingredients and modified starches in wheat based food processing: A review, Trends Food Science Technology 2014 35(1), 32-41 DOI: 10.1016/j.tifs.2013.10.007

[3] Csapó J., Vargáné V. É., Élelmiszerkémia (Food Chemistry), (University of Kaposvár, Kaposvár) 2011 http://www.tankonyvtar.hu/hu/tartalom/ tamop425/0059_elelmiszerkemia/adatok.html

[4] Miguel M., Manso M. A., Lopez-Fandino R., Ramos M., Comparative study of egg white proteins from different species by chromatographic and electrophoretic methods, European Food Research and Technology 2005 221(3), 542-546 DOI: 10.1007/s00217-005-1182-8

[5] Anese M., Nicoli M. C., Massini R., Lerici C. R., Effects of drying processing on the Maillard reaction in pasta, Food Research International 1999 32(3), 193-199 DOI: 10.1016/S0963-9969(99)00076-9

[6] Dexter J. E., Tkachuk R., Matsuo R. R., Amino Acid Composition of Spaghetti: Effect of Drying Conditions on Total and Available Lysine, Journal of Food Science 1984 49(1), 225-228 DOI: 10.1111/j.1365-2621.1984.tb13713.x

[7] Lang E., Zoz F., Iaconelli C., Recovery Estimation of Dried Foodborne Pathogens Is Directly Related to Rehydration Kinetics, PLoS ONE 2016 11(8), e0160844 DOI: 10.1371/journal.pone.0160844

[8] MSZ 6369-1:1985 Flour test methods. Sensory analysis. Scoring and qualification

[9] Singleton V. L., Rossi J. A. Jr., Colorimetry of total phenolics with phosphomolybdic-phosphotungstic acid reagents, American Journal of Enology and Viticulture 1965 16(3), 144-158 DOI: 10.12691/ijebb2-1-5

[10] Benzie I. F., Strain J. J., The ferric reducing ability of plasma (FRAP) as a measure of "antioxidant power": The FRAP assay, Analytical Biochemistry 1996 239(1), 70-76 DOI: 10.1006/abio.1996.0292

[11] Björkstén F., Participation of horseradish oxyperoxidase (compound 3) in interenzymic reaction steps, Biochimica et Biophysica Acta 1968 154(1), 309311 DOI: 10.1016/0005-2744(68)90196-4
[12] Layne E., Spectrophotometric and Turbidimetric Methods for Measuring Proteins (Colowick P. S. and Kaplan N. O., Eds., Methods in Enzymology, Academic Press, Inc., New York) 1957, 447-454 OCLC number: 757246524

[13] MSZ 20500-2:1985 Pastry products. Test methods. Chemical analysis

[14] MSZ ISO 7954:1999 Microbiology - General guidance for enumeration of yeasts and moulds - Colony count technique at $25^{\circ} \mathrm{C}$

[15] ISO 4832:2006 Microbiology of food and animal feeding stuffs - Horizontal method for the enumeration of coliforms - Colony-count technique

[16] MSZ EN ISO 6888-1:2008 Microbiology of food and animal feeding stuffs. Horizontal method for the enumeration of coagulase-positive staphylococci (Staphylococcus aureus and other species). Part 1: Technique using Baird-Parker agar medium (ISO 6888-1:1999)

[17] MSZ EN ISO 6579:2006 Microbiology of food and animal feeding stuffs. Horizontal method for the detection of Salmonella spp. (ISO 6579:2002)

[18] XLSTAT software, Addinsoft 28 West 27th Street, Suite 503, New York, NY 10001 USA

[19] Codex Alimentarius Hungaricus 2-321 Dried pasta products

[20] Bíró G., Élelmiszer-higiénia (Food Hygiene) (Agroinform Kiadó, Educatio) 2014 https : / / www . tankonyvtar.hu/hu/tartalom/tamop425/2011_ 0001_533_ElelmiszerHigienia/index.html

[21] Muyonga J. H., Andabati B., Ssepuuya G., Effect of heat processing on selected grain amaranth physicochemical properties, Food Science and Nutrition 2014 2(1), 9-16 DOI: 10.1002/fsn3.75

[22] Phisut N., Jiraporn B., Characteristics and antioxidant activity of Maillard reaction products derived from chitoan-sugar solution, International Food Research Journal 2013 20(3), 1077-1085

[23] Sajtos L., Mitev A., SPSS kutatási és adatelemzési kézikönyv (SPSS research and data analysis manual) 2007 (Budapest, Alinea Kiadó, 203-245) ISBN: 978-963-9659-08-7 